\title{
Steady-state fluorescence studies on lipase-vesicle interactions
}

\author{
Eduard W.J. Mosmuller ${ }^{\text {a,1 }}$, Eward H.W. Pap ${ }^{\text {b }}$, Anton J.W.G. Visser ${ }^{\text {b }}$ \\ and Johan F.J. Engbersen ${ }^{c}$, $*$ \\ ${ }^{a}$ Dept. of Organic Chemistry, Wageningen Agricultural University, Wageningen (The Netherlands), ${ }^{b}$ Dept. of Biochemistry, \\ Wageningen Agricultural University, Wageningen (The Netherlands) and ${ }^{C}$ Dept. of Organic Chemistry, University of Twente, \\ P.O. Box 217, 7500 AE Enschede (The Netherlands)
}

(Received 8 September 1993)

Key words: Lipase; Vesicle membrane; Protein-membrane interaction; Polymerizable surfactant vesicle; Fluorescence anisotropy; Energy transfer

\begin{abstract}
The interaction of lipase from Candida cylindracea (CCL) with positively charged polymerizable surfactant vesicles was studied by the use of steady-state fluorescence techniques. The phase transition of vesicles composed of nonpolymerized and polymerized $\mathrm{N}$-allylbis[2-(hexadecanoyloxy)ethyl]methylammonium bromide (ABHEMA Br) was determined in the absence of lipase, by measuring the change in fluorescence anisotropy of the membrane probe 1,6-diphenyl-1,3,5-hexatriene (DPH). The phase transition temperature for nonpolymerized vesicles is $49^{\circ} \mathrm{C}$ and for the polymerized analogues $45^{\circ} \mathrm{C}$. Fluorescence anisotropy and resonance energy transfer measurements were used to illustrate the incorporation of the lipase in the vesicle membrane. These studies demonstrated that $\mathrm{CCL}$ is incorporated into the hydrophobic bilayer of the vesicle. By using an interfacial membrane probe 1-[4-(trimethylammonium)phenyl]-6-phenyl-1,3,5-hexatriene $p$-toluene sulphonate, TMA-DPH) and an internal membrane probe (DPH), it could be determined that the enzyme is incorporated more efficiently into nonpolymerized vesicles, and that the penetration of the enzyme into the bilayer is less deep in the case of the polymerized vesicles.
\end{abstract}

\section{Introduction}

Vesicles can be formed from a broad variety of amphiphilic molecules and have well-defined surface properties [1-3]. Due to these characteristics, the application of vesicular systems is versatile, ranging from the use as model systems for biological membranes $[4,5]$ and the reconstitution of membrane proteins [6], to the entrapment of all sorts of compounds including enzymes $[7,8]$. The stability of vesicles can easily be enhanced by the use of polymerizable surfactants.

\footnotetext{
* Corresponding author. Fax: + 3153356024.

1 Present address: Senter, P.O. Box 30732, 2500 GS The Hague, The Netherlands.

Abbreviations: ABHEMA $\mathrm{Br}, \quad N$-allylbis[2-(hexadecanoyloxy) ethyl]methylammonium bromide; $\mathrm{CCL}$, Candida cylindracea lipase; DPH, 1,6-diphenyl-1,3,5-hexatriene; EM, electron microscopy; ET, energy transfer; $F$, fluorescence (intensity); $I_{\perp}$, fluorescence intensity perpendicular to the polarized excitation; $I_{\|}$, fluorescence intensity parallel to the polarized excitation; $r$, anisotropy; RITC, rhodamine $\mathrm{X}$ isothiocyanate; RITC-CCL, rhodamine-labelled Candida cylindracea lipase; $T_{\mathrm{c}}$, phase transition temperature $\left({ }^{\circ} \mathrm{C}\right)$; TMA-DPH, 1-[4-(trimethylammonium)phenyl]-6-phenyl-1,3,5-hexatriene $p$ toluenesulfonate; Trp, tryptophan; Tyr, tyrosine.
}

Polymeric surfactants have proven to be considerably more stable than the nonpolymerized analogues [9]. For practical applications of enzyme-vesicle systems, e.g., for the stabilization of enzymes, the development of drug targeting systems and in order to create microbioreactors, it is desirable to have samples of high stability. Therefore, we were interested in the behaviour of lipase from Candida cylindracea incorporated in polymerizable synthetic surfactant vesicles [10]. In earlier publications we have described the effect of incorporation on enzymatic activity [11] and on stability [12].

We now wish to report a study on the interaction of Candida cylindracea lipase (CCL) with positively charged, polymerizable surfactant vesicles. By the use of fluorescence anisotropy, the microviscosity of the bilayer of nonpolymerized and polymeric $\mathrm{N}$-allylbis[2(hexadecanoyloxy)ethyl]methylammonium bromide (ABHEMA $\mathrm{Br}$ ) vesicles and their phase transition temperatures could be determined.

By the use of fluorescence energy transfer, the incorporation of native CCL from the bulk aqueous phase into the vesicle bilayer was monitored. In addition, anisotropy measurements were used for monitor- 


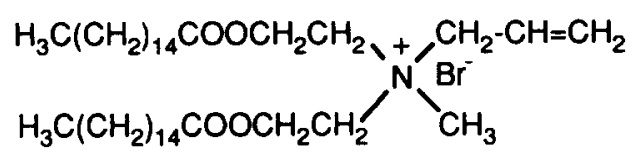

Scheme I. $N$-allylbis[2-(hexadecanoyloxy)ethyl]methylammonium bromide (ABHEMA Br).

ing the interaction between vesicles and lipase modified with a rhodamine label.

\section{Materials and Methods}

Enzymes / reagents. Purification of Candida cylindracea lipase (CCL; lipase OF, Meito Sangyo) and synthesis of the polymerizable surfactant $\mathrm{N}$-allylbis[2(hexadecanoyloxy)ethyl]methylammonium bromide (ABHEMA Br) were described previously [13]. Tris(hydroxymethyl)aminomethane (Tris; $99+\%$ ) and 1,6-diphenyl-1,3,5-hexatriene (DPH; 98\%) were obtained from Janssen Chimica; Sephadex G-25 (superfine) was purchased from Pharmacia. Rhodamine $X$ isothiocyanate (RITC) and 1-[4-(trimethylammonium)phenyl]6-phenyl-1,3,5-hexatriene $p$-toluene sulphonate (TMADPH) were supplied by Molecular Probes. All aqueous solutions were prepared in particle free, demineralized and deionized water, purified by a Seralpur Pro 90C/ Seradest LFM water purification system.

Preparation of rhodamine-labelled CCL. Candida cylindracea lipase was modified with a rhodamine label by mixing $3.46 \mathrm{mg}$ of lipase $(59 \mathrm{nmol})$ in $2 \mathrm{ml}$ of $10 \mathrm{mM}$ Tris- $\mathrm{HCl}$ buffer ( $\mathrm{pH} 9)$ and $0.5 \mathrm{mg}$ (14.5 equiv.) rhodamine isothiocyanate (RITC) in $0.5 \mathrm{ml}$ buffer. After 2 $\mathrm{h}$ reaction time, the labelled protein was separated from the unreacted label by passing the reaction mixture through a Sephadex G-25 column, using $1 \mathrm{mM}$ Tris- $\mathrm{HCl}(\mathrm{pH} 7)$ as an eluent. The label to protein ratio was determined by means of UV/Vis spectrophotometry. In separate measurements, the extinction coefficients $\epsilon$ for RITC at 278 and $578 \mathrm{~nm}$ and for CCL at $278 \mathrm{~nm}$ were determined. The extinction coefficient of lipase at $578 \mathrm{~nm}$ was negligible. The label concentration in the modified enzyme was determined from the absorbance at $578 \mathrm{~nm}$. The protein concentration was calculated from the absorbance at $278 \mathrm{~nm}$, which had to be corrected for the contribution of the absorbance originating from the label at that wavelength. Thus, the label to protein ratio was calculated from Eqn. 1:

$$
\text { label-to-protein ratio }=\frac{\left(\frac{A_{578}}{\epsilon_{578}^{\mathrm{RITC}}}\right)}{\left(\frac{A_{278}-\left\{\frac{A_{578}}{\epsilon_{578}^{\mathrm{RITC}}} \times \epsilon_{278}^{\mathrm{RITC}}\right\}}{\epsilon_{278}^{\mathrm{CCL}}}\right)}
$$

$A=$ absorbance of the labelled protein at $278 \mathrm{~nm}\left(A_{278}\right)$ and at $578 \mathrm{~nm}\left(A_{578}\right), \epsilon=$ molar extinction coefficients for CCL at $278 \mathrm{~nm}$ and RITC at $278 \mathrm{~nm}$ and $578 \mathrm{~nm}$ $\left(\epsilon_{278}^{\mathrm{CCL}}=36700 \mathrm{M}^{-1}, \quad \epsilon_{278}^{\mathrm{RITC}}=11700 \mathrm{M}^{-1}, \quad \epsilon_{578}^{\mathrm{RITC}}=\right.$ $25500 \mathrm{M}^{-1}$ ).

Preparation of vesicle solutions. Unlabelled vesicles were prepared by sonication of dispersions of nonpolymerized or polymeric $\mathrm{N}$-allylbis[2-(hexadecanoyloxy) ethyl]methylammonium bromide. Polymeric ABHEMA $\mathrm{Br}$ was prepared by prepolymerization of the surfactant in tetrahydrofuran via radical polymerization as described previously [11]. Vesicles were provided with membrane probe molecules by mixing stock solutions of nonpolymerized or polymeric ABHEMA $\mathrm{Br}$ in chloroform/ethanol $(5 / 1, v / v)$ with DPH or TMA-DPH stock solutions in chloroform. The solvent was evaporated under a stream of nitrogen and the samples were kept under high vacuum for at least $15 \mathrm{~min}$ in order to remove any traces of organic solvent. Next, the samples were rehydrated with a proper amount of Tris- $\mathrm{HCl}$ buffer (1 mM, pH 7) and subsequently vesiculated by sonication for $10 \mathrm{~min}$ at $60^{\circ} \mathrm{C}$ using a VC-300 Sonics and Materials probe sonifier equipped with a microtip set at output level 3. Before use, all solutions were centrifuged for $30 \mathrm{~min}$ at $15500 \times \mathrm{g}$ in a Sigma $202 \mathrm{M}$ centrifuge, and were passed through a Millipore filter (pore size $0.45 \mu \mathrm{m}$ ) in order to remove any possible titanium particles from the sonifier tip.

Energy transfer measurements. Fluorescence energy transfer studies were carried out on an Aminco fluorimeter DMX-1000 from SLM Instruments with excitation and emission monochromator slits set at $5 \mathrm{~nm}$. The various vesicles stock solutions ( $20 \mathrm{mM}$ ABHEMA $\mathrm{Br}$ : nonpolymerized or polymeric) were titrated to a 50 $\mu \mathrm{g} / \mathrm{ml} \mathrm{CCL}(850 \mathrm{nM}$ ) solution (1 mM Tris- $\mathrm{HCl}, \mathrm{pH}$ 7). The surfactant to label molar ratios were $40: 1$ (DPH) or 50:1 (TMA-DPH). The titrations were carried out at $20^{\circ} \mathrm{C}$. The excitation wavelength was set to $280 \mathrm{~nm}$; the experiments were carried out at room temperature with continuous stirring. The titrations with nonpolymerized vesicles were carried out to a maximum of 300 $\mu \mathrm{M}$ (in the case of DPH as the membrane probe) or $158 \mu \mathrm{M}$ (in the case of TMA-DPH). At a concentration of $158 \mu \mathrm{M}$, the enzyme-vesicle solutions started to flocculate. In the case of titration with polymerized vesicles, this problem does not occur. All measurements were carried out in duplicate, the standard deviation in all cases was less than $3.1 \%$.

Fluorescence anisotropy. Steady-state fluorescence anisotropy measurements were carried out with a home build T-format fluorescence polarization apparatus with single photon counting detection. The excitation wavelength was set to $576 \mathrm{~nm}$ and the emission wavelength to $610 \mathrm{~nm}$. All solutions were stirred continuously during the measurements. The titrations were carried out at $20^{\circ} \mathrm{C}$. The fluorescence anisotropy $r$ was calcu- 
lated from Eqn. 2. All measurements were carried out in duplicate, standard deviation never exceeded $1.9 \%$.

$r=\frac{I_{\|}-I_{\perp}}{I_{\|}+2 \cdot I_{\perp}}$

Phase transition determination of ABHEMA $\mathrm{Br}$ vesicles. The phase transition of nonpolymerized and polymeric ABHEMA $\mathrm{Br}$ vesicle membranes was examined by monitoring the anisotropy of the membrane probe DPH (surfactant to label ratio 500:1). The temperature of the vesicle solutions was increased from $20^{\circ} \mathrm{C}$ to $60^{\circ} \mathrm{C}$ with $2^{\circ} \mathrm{C}$ increments. The temperature in the cuvettes was controlled by the use of a jacketed cuvette holder that was connected to a thermostated water bath (Lauda RMG). The cuvettes were allowed to equilibrate for $15 \mathrm{~min}$ before each measurement; the real temperature was determined by sampling with a thermometer. DPH was excited at $360 \mathrm{~nm}$ and fluorescence was measured at a maximum of $450 \mathrm{~nm}$ (Balzers K45 interference filter) in combination with a cutoff filter (Schott KV399, $3 \mathrm{~mm}$ ).

Anisotropy of RITC-CCL. The incorporation of rhodamine-modified lipase in ABHEMA $\mathrm{Br}$ vesicles was determined by steady-state fluorescence anisotropy measurements. Aliquots of $5 \mathrm{mM}$ nonpolymerized or polymeric ABHEMA $\mathrm{Br}$ vesicles were titrated to solutions of $240 \mu \mathrm{g} / \mathrm{ml}(4.10 \mu \mathrm{M})$ RITC-CCL in $1 \mathrm{mM}$ Tris- $\mathrm{HCl}$ buffer ( $\mathrm{pH} 7$ ). The excitation wavelength was set to $580 \mathrm{~nm}$ and the emission was measured at 613 $\mathrm{nm}$ (Balzers $613 \mathrm{~nm}$ interference filter) in combination with a cutoff filter (Schott RG610, $3 \mathrm{~mm}$ ).

\section{Results and Discussion}

\section{Phase transition of ABHEMA Br bilayers}

The gel to liquid crystalline phase transition in nonpolymerized and polymeric ABHEMA $\mathrm{Br}$ vesicles was determined via fluorescence anisotropy by the use of $\mathrm{DPH}$ as a membrane probe. The DPH molecule is oriented in the hydrophobic core of the bilayer and by this, serves as an excellent probe for studying the order in membrane bilayers $[14,15]$. The gel to liquid transition of the alkyl chains in the vesicle bilayer is characterized by a drastic change in anisotropy. The fluorescence anisotropy versus temperature profile, as depicted in Fig. 1, indicates that the trajectory of the phase transition of ABHEMA Br bilayer is broadened upon polymerization. The phase transition temperature $T_{\mathrm{c}}$, which is defined as the centre of the transition trajectory, for nonpolymerized and polymeric vesicles are valued at $49^{\circ} \mathrm{C}$ and $45^{\circ} \mathrm{C}$. Dorn and Ringsdorf [16] obtained similar results, lowering of $T_{\mathrm{c}}$ upon surface polymerization, with differential scanning calorimetry studies using vesicles from quaternary dialkyl ammo-

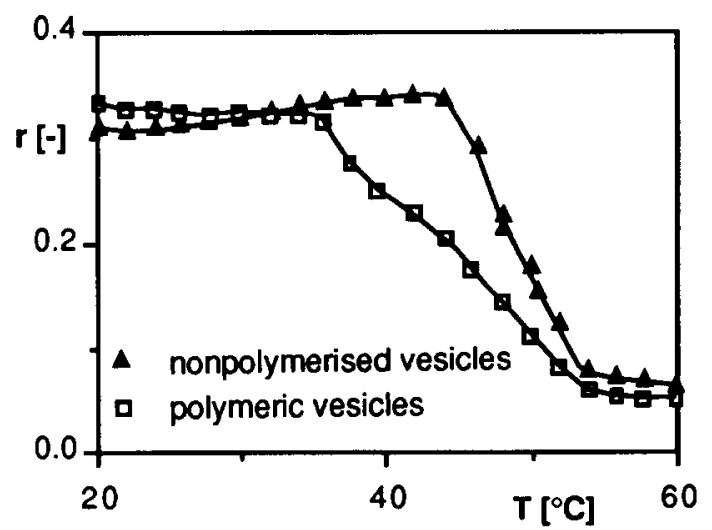

Fig. 1. Phase transition trajectory for nonpolymerized and polymerized ABHEMA Br vesicles when heated from $20^{\circ} \mathrm{C}$ to $60^{\circ} \mathrm{C}$ with $2^{\circ} \mathrm{C}$ increments, determined via fluorescence anisotropy using DPH as the membrane probe (surfactant-to-label ratio: 500:1; excitation wavelength: $360 \mathrm{~nm}$; emission wavelength: $450 \mathrm{~nm}$ ).

nium surfactants with a surface-polymerizable moiety attached to the headgroup.

It is a known phenomenon that alteration in the surfactant headgroup size results in an altered packing density of the headgroups and consequently in the phase transition behaviour of the membrane [17-19]. Headgroups are pulled together upon polymerization, which causes clefts in the bilayer structure [20]. The surfactant chains near these clefts will have a higher degree of freedom, which results in a decrease in $T_{\mathrm{c}}$. DPH molecules, which will be redistributed in the bilayer via translational diffusion, will have an increased rotational motion when they are located in these clefts. As a result of these inhomogeneous structures (clefts in bilayer), the phase transition trajectory will be broadened and shifted to lower values.

\section{Energy transfer studies}

Interaction of proteins with membranes can be monitored by fluorescence energy transfer [21,22]. This method is based on the nonradiative transfer of the excited state energy from a donor to an acceptor molecule. The extent of energy transfer depends mainly on the extent of overlap between the emission spectrum of the donor and the absorption spectrum of the acceptor, and on the orientation and distance between them. The critical distance for energy transfer ranges from $2-5 \mathrm{~nm}$, which is comparable to the radius of Candida lipase $(3.5 \mathrm{~nm}$, derived from references [23] and [24]) and the thickness of synthetic or biological membranes $(4-6 \mathrm{~nm}$ ) [25]. The transfer from protein molecules that remain free in solution (non-incorporated) to the membrane can be considered negligible. The protein that contains the fluorescent amino-acid residues tyrosine (Tyr) and tryptophan (Trp), acts as the donor molecule for electronic excitation energy. The available data on the amino-acid composition of 


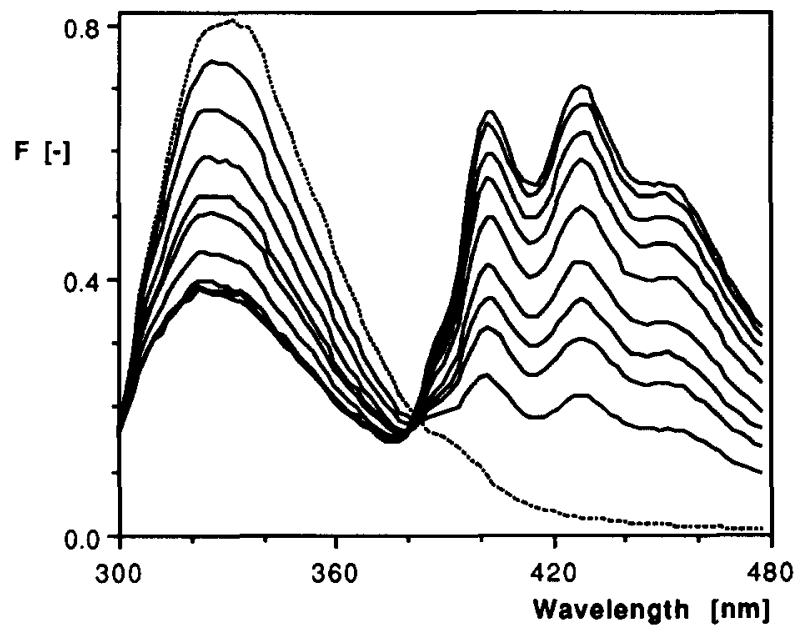

Fig. 2. Changes in the fluorescence spectrum of Candida cylindracea lipase $(50 \mu \mathrm{g} / \mathrm{ml}$ Tris, dashed line) upon addition of $2 \mu \mathrm{l}$ aliquots of $20 \mathrm{mM}$ nonpolymerized vesicles containing $0.4 \mathrm{mM}$ DPH (excitation wavelength: $280 \mathrm{~nm}$ ).

lipase from Candida cylindracea, [26] suggest that CCL contains 4 or 5 Tyr residues and 16 Trp residues, which makes the enzyme very suitable for ET studies.

The membrane probes, DPH and TMA-DPH are used as acceptor molecules for the protein excitation energy. The exact location of the two labels in a bilayer membrane is different. Whereas DPH is located in the hydrophobic core of the membrane, TMA-DPH is considered to reside at the interface of the bilayer $[27,15]$. By the use of an internal and an interfacial label molecule, it was anticipated that information could be obtained of any preferential orientation about the incorporated protein.

A typical example of the change in the fluorescence spectrum of Candida lipase upon titration with DPHlabelled vesicles is depicted in Fig. 2. The decline of the fluorescence peak at $330 \mathrm{~nm}$, which originates from the protein, coincides with an increase of the signal emanating from the label. This clearly indicates that lipase is in close proximity of the probe molecules. Considering the dimensions of the enzyme and the width of the bilayer, the major part of the protein is most likely located in the vesicle bilayer.

The emission maximum of the tryptophan residues is a good probe for the exposure of these groups to the environment. In protein molecules, three different locations for tryptophan residues are distinguished. Peripheral tryptophans, which are fully exposed to the solvent, have an emission maximum from $340-350 \mathrm{~nm}$. The maximum for semi-exposed tryptophans lies from 330-340 nm, and buried residues show maximal emission from 310-330 nm [28]. The shift of the spectral maximum position from $330 \mathrm{~nm}$ for the free lipase (dashed line) to $322 \mathrm{~nm}$ for the incorporated enzyme (solid lines), indicates that mainly peripheral and semi-peripheral Trp residues (emitting at longer wavelength) are involved in the energy transfer.

In order to compare the (extent of) incorporation in nonpolymerized and polymerized vesicles, the decrease in fluorescence at $330 \mathrm{~nm}$ was taken as a measure for binding (Fig. 3). The fluorescence increase at $430 \mathrm{~nm}$, as the result of the energy transfer from the protein to the membrane probe, yielded similar results (not shown). All curves were corrected for the fluorescence of the label in the absence of protein. The steep slopes for titration of enzyme with nonpolymerized vesicles containing DPH or TMA-DPH suggest that lipase is readily incorporated in the vesicle bilayer at temperatures below the phase transition temperature. Since the slopes for the titration curves for both DPH-containing (Fig. 3, left graph) or TMA-DPH-containing (Fig. 3, right graph) nonpolymerized vesicles are identical, it is assumed that the protein is fully dispersed/ partitioned in the hydrophobic core of the vesicle membrane.

The span of time between successive measurements in the titration of $\mathrm{CCL}$ with vesicles, as illustrated in Fig. 2, was $3 \mathrm{~min}$. The span of time, or incubation time,

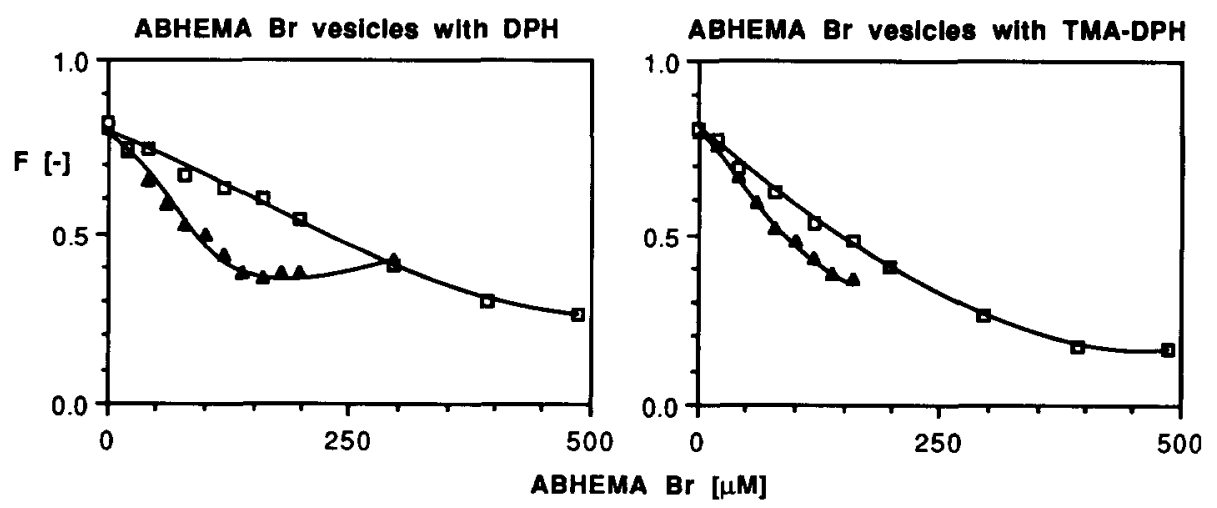

Fig. 3. The fluorescence at $330 \mathrm{~nm}$ (vertical axis) monitored during the titration of a $50 \mu \mathrm{g} / \mathrm{ml} \mathrm{CCL}$ solution with nonpolymerized (A) or polymeric $(\square)$ vesicles containing the internal label DPH (left graph) and interfacial label TMA-DPH (right graph), the ABHEMA Br concentration is plotted on the horizontal axis (excitation wavelength: $280 \mathrm{~nm}$ ). 
between two measurements, however, had no influence on the fluorescence. In separate experiments, it was shown that energy transfer was completed immediately after addition of vesicles to the lipase solution, and that the fluorescence signal did not alter any more with time (for the duration of maximal $1 \mathrm{~h}$ ). The term 'immediately' refers to the minimal time required for recording a fluorescence spectrum from $300-480 \mathrm{~nm}$, which is amounted to $1.5 \mathrm{~min}$.

In the titration curve of lipase with nonpolymerized vesicles containing DPH, an estimation was made for the stoichiometry of the system (for further details see Appendix). At a concentration of $158 \mu \mathrm{M}$ in vesicles the curve shows a minimum value in fluorescence intensity $F$, which suggest saturation of vesicles with enzyme. The enzyme / surfactant ratio is $50 \mu \mathrm{g} / \mathrm{ml}: 160$ $\mu \mathrm{M}$, corresponding to molar ratios of $1: 160$ protein/ surfactant, and 1:0.016 protein/vesicle. Thus one vesicle contains about 60 lipase molecules. As can be deduced from the Appendix, $60 \mathrm{CCL}$ molecules per vesicle means that $1 / 4$ of the available vesicles surface is occupied by lipase.

In the case of polymerized vesicles (Fig. 3, $\square$ ) the slope of the decrease in fluorescence at $330 \mathrm{~nm}$ is less steep than in the case of nonpolymerized vesicles ( $\Delta$ ). This is evidently due to the polymeric nature of the membrane. Surface polymerization changes the distance between neighbouring surfactant headgroups as well as the packing density and order of the alkyl chains in the hydrophobic core of the bilayer. This makes polymerized ABHEMA Br vesicles less accessible for protein than the nonpolymerized counterparts. The difference in slopes of the titration curves with polymeric vesicles containing DPH (left graph), an internal membrane probe, or TMA-DPH (right graph), a surface probe, suggests that CCL penetrates the vesicle bilayer less deeply than in the case of nonpolymerized vesicles.

The initial stage in the incorporation process will mainly be of an electrostatic nature [29,30]. However, lipases undergo structural changes upon contact with surfaces [31-33]. These structural changes generate the formation of an apolar surface around the active site [34], which might lead to complete insertion of the enzyme into the vesicle bilayer $[35,36]$. However, polymerization decreases the accessibility of the bilayer for the enzyme. Incorporation of the protein will take place, but is reduced, as is illustrated by higher saturation concentrations in the titration curves of polymeric vesicles (400-500 $\mu \mathrm{M}$, compared to $160 \mu \mathrm{M}$ for nonpolymerized vesicles). In addition, a decreased accessibility of the polymeric bilayer is accompanied by a phenomenon as described earlier [11]. Directly after mixing of enzyme with polymeric vesicles the activity of the enzyme is very low. After an incubation time of $1 \mathrm{~h}$ the activity of the lipase-vesicle mixture is maximal.
Although fluorescence studies show that incorporation is a rather fast process, the activity of the incorporated enzyme is not immediately maximal. This may be the result of reorientation of the protein in the membrane, or reorientation of the surfactant molecules around the enzyme, which imparts a decreased accessibility of the active site upon incorporation in polymerized vesicles. Thus, incorporation in polymeric vesicles proceeds less facile than in the case of nonpolymerized vesicles and the polymeric nature of the vesiculated surfactant molecules initially lowers the enzymatic activity.

\section{Fluorescence anisotropy of RITC-labelled CCL}

Steady-state fluorescence anisotropy can be used for the characterization of the incorporation process of a protein into a vesicle bilayer. The rotational freedom of the protein will be restricted upon incorporation. Consequently, the anisotropy of the enzyme will rise upon addition of vesicles [22]. This phenomenon was used to monitor the lipase-vesicle interaction.

It was not possible to use native enzyme for this purpose. Due to the high amount of tryptophans in Candida cylindracea lipase [26], a relatively small protein $(58.5 \mathrm{kDa}$ [11]), fluorescence depolarization might be completely due to internal tryptophan-tryptophan energy transfer. This possibility prevents detection of protein-vesicle interaction by anisotropy measurements. Therefore, it was decided to use CCL surfacelabeled with the red dye RITC. The rhodamine moiety is covalently coupled to lysine residues of the enzyme. From Tomizuka's data on the amino-acid composition of Candida cylindracea it can be calculated that CCL contains 15 lysine residues [26]. Under the conditions used, four to five residues were derivatized (Eqn. 1: $A_{278}=0.371$ and $A_{578}=0.480$, see Materials and Methods). The derivatization considerably affected the properties of the enzyme. The specific activity of the labelled enzyme was reduced to $10 \%$ of the activity of the native enzyme. The modified enzyme is less stable than the native enzyme and might be denatured upon derivatization, which was denoted by precipitation of the protein upon prolonged standing. The isoelectric point of the enzyme is also altered, since the isothiocyanate reacts preferentially with the (uncharged) amino groups of the lysine residues under basic conditions. Roberts and Tombs [37] have reported a decrease of 1.2 and $1.0 \mathrm{p} I$ units for two different lipases that were modified with fluorescein isothiocyanate. In our case however, this effect could not be confirmed by isoelectric focussing. The enzyme did not move from the spot where it was administered. This is most likely due to the reduced stability of the modified lipase which causes precipitation of the protein in the gel.

Incorporation of the protein in vesicles should yield a gradual increase in fluorescence anisotropy. However, the anisotropy of the rhodamine modified CCL 


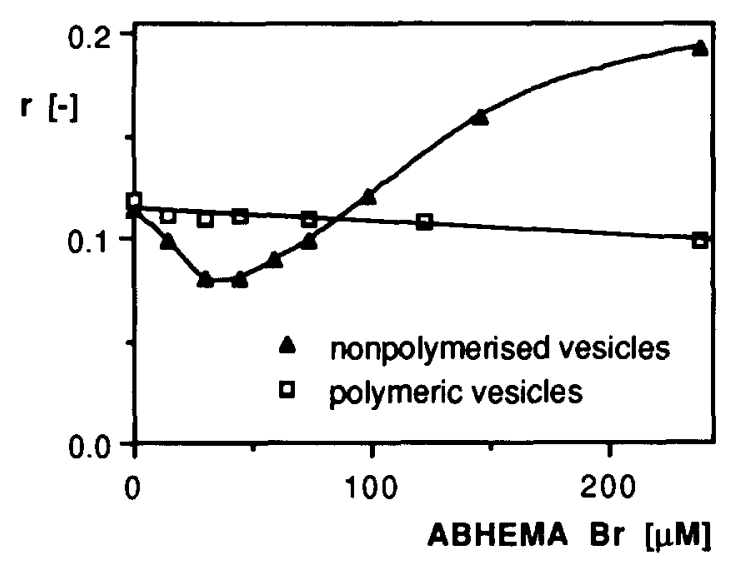

Fig. 4. Anisotropy of rhodamine modified CCL $(240 \mu \mathrm{g} / \mathrm{ml}, 4.1 \mathrm{mM}$, 4-5 rhodamine residues per enzyme molecule) when titrated with aliquots of $5 \mathrm{mM}$ nonpolymerized or polymerized ABHEMA Br vesicle solutions (excitation wavelength: $580 \mathrm{~nm}$; emission wavelength: $613 \mathrm{~nm}$ ).

first shows a decrease in case of titration with nonpolymerized vesicles (Fig. 4). This may be explained by the existence of oligomeric aggregates of the enzyme. Due to derivatization of the lysine residues, the enzyme might tend to aggregate into oligomers because repulsive interactions, which stabilize the monomeric protein, have been diminished. Due to their amphiphilic nature, initial addition of vesicles may induce deaggregation of the oligomeric protein, which results in a decrease of the anisotropy. Further administering of vesicles will lead to an increase in anisotropy due to incorporation of the enzyme in the vesicles. Addition of polymerized vesicles to the modified enzyme solution exhibits almost no change in anisotropy. Obviously, the change in protein structure due to derivatization prevents incorporation of the modified enzyme into polymeric vesicles. It should be noted that covalent labeling can considerably alter the characteristics of the enzyme, which also might affect the incorporation behaviour of the modified protein.

\section{Conclusions}

Fluorescence anisotropy and radiationless energy transfer are suitable techniques to monitor the interaction between lipase and synthetic vesicles. By the use of anisotropy, the phase transition temperature of nonpolymerized and polymeric vesicles could be determined. The results indicate that the packing density in both types of vesicles is distinct. In addition, fluorescence anisotropy and energy transfer studies show that the enzyme is readily incorporated into the membrane. However, the affinity of the enzyme is higher for nonpolymerized vesicles. The lipase cannot penetrate the polymerized bilayer in the same extent as in the case of the nonpolymerized analogues, due to the altered membrane characteristics.

\section{Appendix}

\section{Estimation of protein-to-vesicle ratio}

The mean radius of ABHEMA $\mathrm{Br}$ vesicles is taken as $100 \mathrm{~nm}$ (mean value, derived from EM [11]), which yields an estimated surface area of a vesicle $A_{\mathrm{v}}$ is $125000 \mathrm{~nm}^{2}$.

The radius of CCL, a globular protein with a molecular weight of $58.5 \mathrm{kDa}$, can be estimated from gel permeation chromatography [24] or from binding/ adsorption measurements [23] and is valued at $3.5 \mathrm{~nm}$. The minimal area occupied by a lipase molecule $A_{\mathrm{CCL}}$ on the vesicle surface is valued at $50 \mathrm{~nm}^{2}$.

At a concentration of a $50-60 \mu \mathrm{g} / \mathrm{ml} \mathrm{CCL}\left(C_{\mathrm{CCL}}=\right.$ $1 \mu \mathrm{M})$ and at a ABHEMA $\mathrm{Br}$ monomer concentration of $10 \mu \mathrm{M}$, which corresponds to a vesicle concentration $C_{\mathrm{v}}$ of $10^{-4} \mu \mathrm{M}$ (reported number of surfactant molecules per vesicle: $80000-100000$ [38]), the enzyme-to-monomer surfactant molar ratio is $1: 10$, the enzyme-to-vesicle molar ratio is $1: 10^{-4}$ and the enzyme-to-vesicle surface area is thus valued at $4: 1$ $\left(C_{\mathrm{CCL}} \cdot A_{\mathrm{CCL}}: C_{\mathrm{v}} \cdot A_{\mathrm{v}}=1 \cdot 50: 10^{-4} \cdot 125000\right)$.

\section{Acknowledgements}

We are grateful to Ing. A. van Hoek for technical assistance. We also thank Dr. M.C.R. Franssen for fruitful discussions.

\section{References}

1 Fendler, J.H. (1982) Membrane mimetic chemistry, John Wiley and Sons, New York.

2 Kunitake, T. (1992) Angew. Chem. Int. Ed. Eng. 31, 709-726.

3 Ringsdorf, H., Schlarb, B. and Venzmer, J. (1988) Angew. Chem. Int. Eng. 27, 113-158.

4 Bader, H., Dorn, K., Hupfer, B. and Ringsdorf, H. (1985) Adv. Polym. Sci. 64, 1-62.

5 Papahadjopoulos, D. and Kimelberg, H.K. (1974) Prog. Surf. Sci. 4, 141-232.

6 Eytan, G.D. (1982) Biochim. Biophys. Acta 694, 185-202.

7 Fendler, J.H. (1985) Chemtech 15, 686-691.

8 Gregoriadis, G. (1984) Liposome Technol., Vol. 2, CRC Press, Boca Raton, FL.

9 Paleos, C.N. (1990) J. Macromol. Sci. Rev. Macromol. Chem. Phys. C30, 379-404.

10 Mosmuller, E.W.J. and Engbersen, J.F.J. (1990) in Proceedings 3rd Netherlands Biotechnology Congress 1990 (Breteler, H., Beudeker, R.F. and Luyben, K.C.A.M., eds.), Vol. 1, Netherlands Biotechnological Society, Zeist.

11 Mosmuller, E.W.J., Franssen, M.C.R. and Engbersen, J.F.J. (1993) Biotechnol. Bioeng. 42, 196-204.

12 Mosmuller, E.W.J., Jongejan, H., Franssen, M.C.R. and Engbersen, J.F.J. (1993) Biocatal., in press.

13 Kippenberger, D., Rosenquist, K., Odberg, L., Tundo, P. and Fendler, J.H. (1983) J. Am. Chem. Soc. 105, 1129-1135.

14 Lakowicz, J.R. (1980) J. Biochem. Biophys. Methods 2, 91-119.

15 Prendergast, F.G., Haugland, R.P. and Callahan, P.J. (1981) Biochemistry 20, 7333-7338.

16 Dorn, K. and Ringsdorf, H. (1984) Contemp. Top. Polym. Sci. 5, $73-100$. 
17 Edwards, K. and Almgren, M. (1992) Langmuir 8, 824-832.

18 Malliaris, A. (1988) Prog. Colloid Polym. Sci. 76, 176-182.

19 Sanderman, H., Jr. (1978) Biochim. Biophys. Acta 515, 209-237.

20 Nome, F., Reed, W., Politi, M., Tundo, P. and Fendler, J.H. (1984) J. Am. Chem. Soc. 106, 8086-8093.

21 Devaux, D.F. and Seigneuret, M. (1985) Biochim. Biophys. Acta $822,63-125$.

22 Lakowicz, J.R. (1983) Principles of fluorescence spectroscopy, 496 pp., Plenum Press, New York.

23 Roberts, G.A. and Tombs, M.P. (1987) Biochim. Biophys. Acta 902, 327-334.

24 Siegel, L.M. and Monty, K.J. (1966) Biochim. Biophys. Acta 112, 346-362.

25 Gennis, R.B. (1989) in Biomembranes: Molecular structure and function (Cantor, C.R., ed.), 533 pp., Springer, New York.

26 Tomizuka, N., Ota, Y. and Yamada, K. (1966) Agric. Biol. Chem. 30, 1090-1096.

27 Mulders, F., Van Langen, H., Van Ginkel, G. and Levine, Y.K. (1986) Biochim. Biophys. Acta 859, 209-218.

28 Burstein, E.A., Vedenkina, N.S. and Ivkova, M.N. (1973) Photochem. Photobiol. 18, 263-279.

29 Torchilin, V.P., Omel'yanenko, V.G., Klibanov, A.L., Mikhailov,
A.I., Gol'danskII, V.I. and Smirnov, V.N. (1980) Biochim. Biophys. Acta 602, 511-521.

30 Wolbert, R.B.G., Hilhorst, R., Voskuilen, G., Nachtegaal, H., Dekker, M., Van 't Riet, K. and Bijsterbosch, B.H. (1989) Eur. J. Biochem. 184, 627-633.

31 Brady, L., Brzozowski, A.M., Derewenda, Z.S., Dodson, E., Dodson, G., Tolley, S., Turkenburg, J.P., Cristiansen, L., Huge-Jensen, B., Norskov, L., Thim, L. and Menge, U. (1990) Nature 343, 767-770.

32 Schrag, J.D., Li, Y., Wu, S. and Cygler, M. (1991) Nature 351, 761-764.

33 Winkler, F.K., D'Arcy, A. and Hunziker, W. (1990) Nature 343, 771-774.

34 Brzozowski, A.M., Derewenda, U., Derewenda, Z.S., Dodson, D.M., Turkenburg, J.P., Björkling, F., Huge-Jensen, B., Patkar, S.A. and Thim, L. (1991) Nature 351, 491-494.

35 Norde, W. and Lyklema, J. (1991) J. Biomater. Sci. 2, 183-202.

36 Zakim, D. and Scotto, A.W. (1989) Methods Enzymol. 171, 253-264.

37 Tombs, M.P. and Blake, G.G. (1982) Biochim. Biophys. Acta 700, $81-89$.

38 Fendler, J.H. (1984) Chem. Brit. 1098-1103. 